Georgia State University

ScholarWorks @ Georgia State University

Counseling and Psychological Services Faculty Department of Counseling and Psychological Publications

2017

\title{
Racial Identity Invalidation With Multiracial Individuals: An Instrument Development Study
}

\author{
Marisa Franco \\ Georgia State University, mfranco@gsu.edu \\ Karen M. O'Brien \\ University of Maryland at College Park, kmobrien@umd.edu
}

Follow this and additional works at: https://scholarworks.gsu.edu/cps_facpub

Part of the Counseling Psychology Commons

\section{Recommended Citation}

Franco, Marisa and O'Brien, Karen M., "Racial Identity Invalidation With Multiracial Individuals: An Instrument Development Study" (2017). Counseling and Psychological Services Faculty Publications. 3. https://scholarworks.gsu.edu/cps_facpub/3

This Article is brought to you for free and open access by the Department of Counseling and Psychological Services at ScholarWorks @ Georgia State University. It has been accepted for inclusion in Counseling and Psychological Services Faculty Publications by an authorized administrator of ScholarWorks @ Georgia State University. For more information, please contact scholarworks@gsu.edu. 
Racial Identity Invalidation with Multiracial Individuals: An Instrument Development Study 


\begin{abstract}
Objectives. Racial identity invalidation, others' denial of an individual's racial identity, is a salient racial stressor with harmful effects on the mental health and well-being of Multiracial individuals. The purpose of this study was to create a psychometrically sound measure to assess racial identity invalidation for use with Multiracial individuals $(N=497)$. Methods. The present sample was mostly female $(75 \%)$ with a mean age of 26.52 years $(S D=9.60)$. The most common racial backgrounds represented were Asian/White (33.4\%) and Black/White (23.7\%).

Participants completed several online measures via Qualtrics. Results. Exploratory factor analyses revealed three Racial Identity Invalidation factors: Behavior Invalidation, Phenotype Invalidation, and Identity Incongruent Discrimination. A confirmatory factor analysis provided support for the initial factor structure. Alternative model testing indicated that the bifactor model was superior to the three-factor model. Thus, a total score and/or three subscale scores can be used when administering this instrument. Support was found for the reliability and validity of the total scale and subscales. In line with the Minority Stress theory, challenges with racial identity mediated relationships between racial identity invalidation and mental health and well-being outcomes. Conclusions. Our findings highlight the different dimensions of racial identity invalidation and indicate their negative associations with connectedness and psychological wellbeing.
\end{abstract}

Keywords: Racial Identity; Racial Identity Invalidation: Biracial; Multiracial; Racial Discrimination 
Racial Identity Invalidation with Multiracial Individuals: An Instrument Development Study

Racial identity invalidation, the denial or misperception of another's racial identity, persists at interpersonal and societal levels, despite the negative consequences of this stressor on Multiracial individuals (Lou, Lalonde, \& Wilson, 2011; Sanchez, 2010). Specifically, racial identity invalidation detrimentally affects perception of self, self-esteem, motivation, psychological, and physical health (Coleman \& Carter, 2007; Nishimura, 2004; Rockquemore \& Brunsma, 2002; Townsend, Markus, \& Bergsieker, 2009), is related to increased suicidal thoughts and rates of suicide attempts (Campbell \& Troyer, 2007), and threatens groupidentification and social status of Multiracial individuals (Campbell \& Troyer, 2007; Romo, 2011). Although racial identity invalidation is one of the most potent racial stressors for Multiracial individuals (Shih \& Sanchez, 2005), the measurement of this construct has been underdeveloped, calling into question the validity of past racial identity invalidation research. For research on this construct to progress so that the stress of racial identity invalidation can be mitigated, a reliable and valid measure of racial identity invalidation for use with Multiracial individuals must be constructed. Thus, the purpose of this study was to develop an instrument to assess racial identity invalidation for Multiracial individuals and test its psychometric properties.

Definitions of racial identity invalidation have varied considerably. Some studies define invalidation tautologically as the invalidation of racial identity (Nishimura, 2004; Rockquemore \& Brunsma, 2002), whereas others highlight pressure to identify as Monoracial (Buckley \& Carter, 2004), questioning of one's identity (Rockquemore, 2002), tension between ascribed and internal identities (Khanna, 2010; Lou et al., 2011; Salahuddin \& O’Brien, 2011), forced-choice racial identity situations (Sanchez, 2010; Shih \& Sanchez, 2005), lack of support in identity choice (Coleman \& Carter, 2007), racial inauthenticity accusations (Romo, 2011), and identity 
denial (Townsend et al., 2009). With the variability of definitions of identity invalidation across studies, the following comprehensive definition of this construct was created for this study and is inclusive of prior definitions and research findings: racial identity invalidation is rooted in historical classifications of racial groups as exclusive, essentialized, and hierarchical (Rockquemore \& Laszloffy, 2003). It occurs when there is misalignment between an individual's self-defined racial identity and the way that others perceive them within a particular context (Rockquemore \& Brunsma, 2004; Rockquemore, Brunsma, \& Delgado, 2009). Invalidation can manifest directly or indirectly when others passively misperceive or actively deny an individual's self-defined race. Forms of invalidation include lack of acceptance of an individual's racial identity (e.g., "you are not actually Multiracial") or imposition of a racial identity (e.g., "though you think you are Multiracial, you are actually Black").

\section{Multiracial Identity}

Current racial identity theorists employ an ecological approach to Multiracial identity, which emphasizes the fluid and changing nature of Multiracial identities in reaction to context. Theorists recognize that Multiracial individuals' identity development is variable, non-linear and influenced by situational, interpersonal, and societal factors (Rockquemore et al., 2009). To assume that Multiracial individuals, as a group, inhabit the same predictable stages of identity development, might be akin to assuming that the racial identity formation of all Monoracial individuals occurs in a uniform manner; there is significant diversity of racial backgrounds, life experiences and societal influences that play a role in racial identity development for Multiracial people (Rockquemore \&Brunsma, 2001; Rockquemore et al., 2009). This ecological framework builds on early sociological Symbolic Interactionist theories, which indicate that identity is shaped through social interaction - and that individuals are active agents in shaping their 
identities (Cooley, 1902; Rockquemore et al., 2009). Because of the role of social forces in identity development, Multiracial identity theorists propose that racial identity invalidation is a central experience that affects the identity development of Multiracial individuals (Rockquemore et al., 2009).

Racial identity invalidation is particularly salient for Multiracial individuals because of the historical invisibility of this group within America's racial system (Shih \& Sanchez, 2005; Tashiro, 2002; Townsend et al., 2009). Indeed, only in the year 2000 did the U.S. Census first permit Multiracial individuals to identify with more than one race (Townsend et al., 2009; U.S. Census Bureau, 2010). This Monoracist system was founded on the premise that race is a biological reality, rather than a form of personal identity, and that racial groups are homogenous and separate (Rockquemore et al., 2009; Shih \& Sanchez, 2005). Within this system, Multiracial identities are perceived as illegitimate. Because of the increased susceptibility to racial identity invalidation among Multiracial individuals living in a Monoracist racial society, the current study focuses on the racially invalidating experiences of self-identified Multiracial individuals.

\section{Contributors to Invalidation}

Although research on racial identity invalidation is still developing, the existing literature highlights two major contributors to racial identity invalidation: appearance and behaviors.

Multiracial individuals often possess an appearance that is not deemed racially prototypical that can result in rejection from Monoracial groups with whom they might identify (Khanna, 2004;

Rockquemore \& Brunsma, 2002; Townsend et al., 2009). Relatedly, their race may be ambiguous, provoking questions such as "What are you?" (Miville et al., 2005). Furthermore, when Multiracial people's behaviors do not adhere to racial stereotypes or established cultural practices, they may be barred from identifying with certain groups (Franco, Katz, \& O’Brien, 
2016; Khanna, 2004; Townsend et al., 2009) or forced to adhere to stereotypes or gain cultural knowledge to be accepted (Romo, 2011). In a seminal article on invalidation among Multiracial people, some Multiracial people were "hazed" by having to have sex, steal, or denigrate all White people to demonstrate their allegiance to a racial group (Root, 1998).

\section{Minority Stress Theory and Racial Identity Invalidation}

Minority stress theory posits that stigma, discrimination, and marginalization create a hostile environment for minority group members that contribute to negative health outcomes (Meyer, 2003). Minority stressors are unique, meaning they extend beyond stress faced by all people, chronic, because they reflect underlying social structures and thus are ever-present, and socially-based, stemming from interactions among individuals and institutions. Meyer (2003) suggested that stressors arise because of the discrepancy between the perspective of the minority individual and the larger society.

Thus, racial identity invalidation can be conceptualized as a type of minority stress because the root of racial identity invalidation lies in the discrepancy between self and societal understandings. Societal assumptions about racial categories, fueled by years of historical exclusion of Multiraciality in public discourse (Khanna, 2010), are internalized by members of society rendering Multiracial people vulnerable to racial identity invalidation via interpersonal interactions. Discriminatory experiences, which might include invalidation, are a prevalent issue for Multiracial individuals (Brackett et al., 2006; Buckley \& Carter, 2004; Herman, 2004), are perpetrated by both majority and minority group members (Brackett et al., 2006; Rockquemore \& Brunsma, 2002), and relate to psychological distress (Jackson, Yoo, Guevarra \& Harrington, 2012; Salahuddin \& O’Brien, 2011). Moreover, racial identity invalidation harms psychological and physical health (Coleman \& Carter, 2007; Nishimura, 2004; Rockquemore \& Brunsma, 
2002; Townsend et al., 2009), relates to suicidal ideation and attempts (Campbell \& Troyer, 2007), and negatively affects affiliations with others (Campbell \& Troyer, 2007; Romo, 2011).

According the minority stress model, invalidation may contribute to the development, continuation, and proliferation of mental health concerns. Discriminatory experiences impact individuals from marginalized groups not only when they directly experience the stressor, but at all times, as the individual may be in a constant state of vigilance for rejecting experiences (Meyer, 2003). Furthermore, invalidation often occurs during critical periods in identity development, such as adolescence and young adulthood, and subsequently can compromise an individual's sense of self and identity, contributing to increased susceptibility for psychological distress throughout the lifespan (Franco et al., 2016; Meyer, 2003).

Consistent with minority stress theory, racial identity invalidation is expected to become internalized, subsequently contributing to an internalized lack of sense of identity or belongingness with any racial group, which then relates to poor mental health outcomes. Multiracial people who experience invalidation may perceive that society has a poor evaluation of the Multiracial group (Sanchez, 2010), which might constrain their ability to identify as Multiracial as these public perceptions can become internalized. Thus, racial identity invalidation is first hypothesized to become internalized and then manifest as challenges with racial identity (i.e., a lack of sense of identity or belongingness with any racial group) because the development of a healthy racial identity is, in part, contingent on others acknowledging, reflecting, and affirming one's identity (Rockquemore \& Brunsma, 2002). Furthermore, minority stress theory indicates that negative internationalization of discriminatory experiences (e.g., invalidation manifesting as racial identity challenges) subsequently leads to negative health outcomes and diminished self-esteem. Thus, racial identity invalidation is hypothesized to relate to increased 
depression and diminished self-esteem, and this relationship is expected to be mediated by challenges with racial identity (operationalized as a lack of sense of identity or belongingness with any racial group).

Meyer (2003) also argued that minority stress engenders alienation. Specifically, racial invalidation may indicate to Multiracial individuals that their perspectives and experiences regarding their racial identity are invalid, fostering a subjective loneliness. Racial invalidation also indicates to the Multiracial person that their identity is illegitimate, leaving them excluded from embracing a racial community and provoking feelings of cultural homelessness (Vivero \& Jenkins, 1999). Multiracial individuals' pressure to identify with certain groups may propound feelings of disconnection from racial communities (Campbell \& Troyer, 2007). Thus, the invalidation of a Multiracial person's racial identity may make them question their belongingness, resulting in feelings of racial homelessness and loneliness.

\section{Group Differences in Experiences of Invalidation}

Currently, the largest subgroups of Multiracial individuals in the United States are Asian/White and Black/White groups (U.S. Census, 2010), and despite the need for research on Multiracial individuals of various Multiracial subgroups, most of the existing research on Multiracial individuals has pertained to these groups (see Charmaraman, Woo, Quach, \& Erkut, 2014 and Edwards \& Pedrotti, 2008 for reviews). Extant research indicates that the rule of hypodescent has been applied broadly to these groups to maintain White dominance, with this rule more stringently applied to African-descended Multiracial individuals than Asian Multiracial individuals (Gullickson \& Morning, 2011; Herman, 2004; Herman, 2010; Ho et al., 2011; Roth, 2005). Asian/White Multiracial individuals are more likely to be perceived as White or Multiracial (Gullickson \& Morning, 2011; Herman, 2010), and more likely to identify as such 
(Harris \& Sim, 2002; Lee \& Bean, 2004). One reason why Black/White Multiracial individuals may have less latitude in how they are perceived racially, compared to Asian/White Multiracial individuals, is because the one-drop rule was created specifically for the case of Black/White Multiracial individuals to confine this group to slavery, regardless of their White ancestry (Ho et al., 2013; Rockquemore \& Laszloffy, 2003). This has led to much of the African American population being of mixed race descent, making it difficult to differentiate between those who were mixed by immediate parentage (children of interracial families) and those who were racially mixed over generations (i.e., most Black Americans; Rockquemore et al., 2009). Contrastingly, Asian/White individuals may be more easily recognized as phenotypically different than their Monoracial Asian counterparts. This claim is supported by research that indicates that Black/White Multiracial individuals are more likely to be defined by their minority race than Asian/White individuals (Herman, 2010; Ho et al., 2010).

Moreover, Asian/White Multiracial individuals may feel more validated in identifying as Multiracial because in contrast to Western cultural orientations, Eastern orientations emphasize dialecticism: tolerance for change, fluidity, contradiction, and inconsistencies within the self (Shih, Sanchez, \& Garcia, 2010). Eastern collectivistic orientations may emphasize a conception of the self that is responsive and malleable based on context, whereas Western cultures value a "true" self that is immutable, regardless of setting. Dialecticism emphasizes that inconsistencies are an inherent part of existence, rather than a catalyst for concern (English \& Chen, 2007). Accordingly, Asian/White Multiracial individuals may feel less pressure to align with one of their racial backgrounds, and more tolerance for the versatility of their Multiracial identities.

\section{Measurement of Racial Identity Invalidation in the Multiracial Literature}

Despite the importance of racial identity invalidation for Multiracial individuals, this 
construct has been measured insufficiently. Prior research has used a single item scale to assess racial identity invalidation (i.e., "I consider myself Biracial, but I experience the world as a Black person;" Coleman \& Carter, 2007; Rockquemore \& Brunsma, 2002). This item is limiting, as it conflates identity with invalidation and does not account for racial invalidation experienced by Monoracially-identifying Multiracial individuals. Furthermore, it assumes that one is either always invalidated or never invalidated, though invalidation is contextually bound and may occur on a spectrum (Rockquemore et al., 2009). Also, the measure was created for use solely with Black/White Biracial individuals. Other studies also have measured racial identity invalidation in problematic ways. One study employed a three-item measure, with no mention of an instrument development process or validity testing (Sanchez, 2010). Another study compared an interviewer's assessment of a Biracial individuals race with self-report (Campbell \& Troyer, 2007), despite the fact that interviewer's racial perceptions were biased by their racial backgrounds (Hill, 2002).

More recently, two studies created scales to measure Multiracial people's experiences of risk and resilience. The Multiracial Experiences Scale (Yoo, Jackson, Guevarra, Miller, \& Harrington, 2015) contained subscales that were similar to but distinct from racial identity invalidation: Multiracial discrimination and perceived racial ambiguity. The discrimination subscale was broader than identity invalidation, and included general discriminatory experiences such as getting picked on and assaulted because of race. The ambiguity subscale assessed curiosity surrounding racial background more so than miscategorization. In addition, the Multiracial Challenges and Resilience Scale (Salahuddin \& O’Brien, 2011) included items assessing racial identity invalidation as part of a larger instrument measuring Multiracial individual's challenges and resiliencies. However, the items on this scale did not load as 
hypothesized. Two similar subscales emerged from the factor analyses, including one that that measured others' surprise and disbelief regarding the participant's racial heritage and another that measured racial identity challenges, defined as feeling a lack of sense of identity and/or not belonging in a particular racial group. Surprise and Disbelief may comprise aspects of invalidation, but does not capture the concept in its entirety. Two out of five of the items on the Surprise and Disbelief scale measured others' surprise over a Multiracial individual's relation to a family member, which differs from invalidation because the Multiracial individual may indeed feel that their race is different from their family member, and thus, not feel invalidated. The other subscale, Challenges with Racial Identity differs from invalidation because invalidation measures how others treat the Multiracial individual, rather than their internal feelings about themselves. Furthermore, neither of these measures addresses central catalysts for invalidation, indicated by the literature, such as appearance and behaviors, indicating that these measures have not yet fully captured the experiences of racial identity invalidation.

Thus, the purpose of the present study was to create an instrument to assess racial identity invalidation and to test its psychometric properties. The instrument was hypothesized to have adequate reliability and test-retest reliability. Grounded in minority stress theory, the validity of the instrument was investigated through an examination of its expected association with theoretically-related constructs. Specifically, invalidation was hypothesized to be associated positively with depression, racial homelessness, and loneliness, and negatively with self-esteem. It also was expected to be associated positively with discrimination, a more traditional form of minority stress. We also expected that the scales on the measure would account for variance above that explained by a similar measure: Surprise and Disbelief (Salahuddin \& O’Brien, 2011). Last, based on Minority Stress Theory, we hypothesized that invalidation would relate to 
Challenges with Racial Identity (a lack of sense of identity or belongingness with any racial group), and also that Challenges with Racial Identity (representing the internalization of invalidating experiences) would at least partially mediate relationships between racial identity invalidation and mental health and well-being outcomes. Because of the variation in definitions of invalidation reported by the literature, we did not hypothesize a pre-existing factor structure.

\section{Method}

\section{Definition and Item Development}

Before creating items, the first author read the literature on racial identity invalidation starting with seminal works (e.g., Rockquemore \& Brunsma, 2002, Rockquemore et al., 2009, and Root, 1992). Research indicated that racial invalidation could be subtle or blatant, and was especially prevalent for individuals identifying as Multiracial. The author created a definition that was inclusive of prior conceptualizations that could be used as a framework for guiding item development (i.e., see definition in introduction). Feedback on the definition was solicited from three doctoral students, two assessment experts, and three experts on Multiracial research. One expert researched outcomes for Black/White Multiracial individuals, and the others studied the Multiracial community as a whole. Items were developed by the primary investigator based on the literature and the definition. Efforts were made to construct items that reflected both passive misperception and active denial of one's race.

Fifty-seven items were presented to four doctoral students in psychology and one doctoral-level psychologist who is an assessment specialist. Feedback from this group was used to improve clarity. The revised 57 items then were presented to an expert on Multiracial research and measurement who reviewed the items for clarity, readability, and adherence to the definition of invalidation. Based on the feedback, some items were added and others were deleted. 
The revised instrument of 35 items was administered to a group of 15 individuals for additional feedback. Comments indicated that some of the items were redundant, so the instrument was reduced to 29 items. The shortened instrument was presented to two professors and one doctoral student; all conducted research on Multiracial individuals. They were invited to comment on the items and the degree to which items adhered to the definition of the construct, which led to changes to increase clarity, the deletion of items to eliminate redundancy, and the addition of more items that addressed invalidation that occurs when behaviors are misaligned with racial stereotypes. Also, items were added after viewing 10 videos of Black/White Multiracial individuals discussing their most hurtful experiences of racial identity invalidation. The final instrument was comprised of 30 items, each having a frequency and distress component. Specifically, participants rated how often each item occurred on a scale from 1 (never) to 6 (almost always) and how distressed they were by this experience on a scale from 1 (not at all distressed) to 6 (extremely distressed). These rating scales were selected based on Salahuddin and O'Brien's (2011) instrument, which measured challenges and resiliencies in the lives of Multiracial individuals. The frequency component was used for analyses, as participants who did not report experiencing an item did not complete the accompanying distress scale for that item. Utilizing frequency, rather than distress of invalidating experiences corresponds to minority stress theory's emphasis on the role of "hostile external environments" as a requisite to internal minority stress for marginalized groups (Meyer, 2003). Furthermore, frequency, as an external experience, corroborates the aforementioned definition of invalidation as an experience that others perpetrate on the Multiracial individual. Last, utilizing the frequency component for analyses allowed for findings to connect with prior research on racial invalidation, which focused exclusively on the experience of invalidation rather than internal distress in reaction to the 
phenomenon (Campbell \& Troyer, 2007; Coleman \& Carter, 2007; Rockquemore \& Brunsma, 2001).

The items then were administered to another group of 10 Multiracial individuals, who provided additional feedback. Efforts were made to recruit individuals of varied Multiracial backgrounds for this pilot test. The reviewers represented various racial backgrounds—including Multiracial Asian, Black, White, Native, and Hispanic individuals. Several items were altered, resulting in a final instrument of 30 items. Items on the measure are suitable for an $8^{\text {th }}$ grade reading level and above (Flesch, 1948).

\section{Participants}

A total of 922 people began the survey and 542 completed the measures $(58.8 \%$ response rate). A manipulation check was included where participants were told to click "agree" for one item. Forty-five participants failed the manipulation check, leaving a sample of 497 participants who had completed all measures within the survey and passed the manipulation check.

Participants were mostly female (75\% female, $24 \%$ male, $1 \%$ other identity) and ranged in age from 18 to 63 years old, with a mean age of $26.52(S D=9.60$ years). Approximately $40.7 \%$ of participants reported their family income as greater than $\$ 80,000$ per year, $29.4 \%$ earned between $\$ 40$ and 79,000, and 29.9\% earned below $\$ 40,000$. Most (64.8\%) reported being "completely heterosexual", whereas a few (3.4\%) reported being "completely gay" and the remainder $(31.8 \%)$ rated themselves as between the poles. Approximately $9.5 \%$ of the sample finished high school, $32.0 \%$ finished some college, $7.4 \%$ finished an associate's degree, $27.4 \%$ finished a bachelor's degree, and $20.5 \%$ reported a graduate degree. The most common racial backgrounds represented were Asian/White (33.4\%), Black/White (23.7\%), Black/Asian (5.0\%), and Hispanic/White (4.6\%). 


\section{Procedure}

Participants accessed measures through the Qualtrics website, an online survey platform. The initial page displayed the informed consent. After, participants were presented with the measures listed below. The Racial Identity Invalidation instrument was administered first, followed by the scales used to assess validity.

Recruitment. To recruit participants, the researcher sent emails to personal contacts. All recruitment materials requested participation from individuals who self-identify as Multiracial. The study also was advertised through online groups catering to Multiracial individuals, including SWIRL and MAViN. An email was sent out to all Multiracial-identifying individuals at a large mid-eastern university using the university registrar database. As incentive, participants were invited to enter a raffle for one of two $\$ 25$ gift cards.

\section{Measures}

Demographic questionnaire. The demographic questionnaire assessed age, gender, sexual orientation, education level, income, and racial identification.

Racial identity invalidation. See the item development section.

Depressive symptoms. The 20-item Center for Epidemiological Studies Depression Scale was used to assess depressive symptoms and included six scales that measured depressed mood, guilt and worthlessness, helplessness and hopelessness, psychomotor retardation, loss of appetite, and sleep disturbance (Radloff, 1977). Sample items included "I did not feel like eating; my appetite was poor" and "I felt depressed." Participants marked the frequency that they experienced the symptoms ranging from 1 (rarely or none of the day; less than 1 day) to 4 (most or all of the time; 5-7 days). Negative items were reverse-coded and ratings of items were summed, with high scores indicating significant depression. Internal consistency ratings were 
high for Multiracial samples, ranging from .84 to .93 (Brittian, Umaña-Taylor, \& Derlan, 2013; Sanchez, 2010; Sanchez, Shih \& Garcia, 2009), for which the measure correlated negatively with well-being (Sanchez et al., 2009) and self-esteem, and positively with anxiety (Brittian et al., 2013). The reliability estimate for the present research was .92 .

Self-esteem. Self-esteem was measured using the 10-item Rosenberg Self-Esteem Scale (Rosenberg, 1979). An example item is "On the whole, I am satisfied with myself." Items were measured on a Likert scale ranging from 1 (strongly disagree) to 4 (strongly agree). Several items were reverse-scored items and all items were summed, with high scores indicating high self-esteem. Internal consistency ratings for Multiracial samples have ranged from .82 to .92 (Binning, Unzueta, Huo, \& Molina, 2009; Brittian et al., 2013). The measure correlated positively with self-acceptance and negatively with depression for a Multiracial sample (Brittian et al., 2013). The reliability estimate for the participants in this study was .91 .

Racial homelessness. The 14-item Cultural Homelessness scale includes three components: (a) Lack of cultural home (e.g., "I am an ethnic or cultural minority everywhere I go"), (b) Lack of attachment to any one racial group (e.g., "I feel that I don't belong to any ethnic or cultural group."), and (c) Desire for a racial group (i.e., "Finding a cultural home is important to me"; Navarrete \& Jenkins, 2011). For the present study, "culture" was replaced by “race." Items were measured on a Likert scale ranging from 1 (strongly disagree) to 5 (strongly agree). Scores on all items were averaged into one mean score, with high scores representing more experiences of racial homelessness (Navarrete \& Jenkins, 2011). Alpha rates of .71 and .84 were reported for a Multiracial sample (Navarrete \& Jenkins, 2011). Using a sample composed of approximately $25 \%$ Multiracial participants, racial homelessness negatively related to affirmation, belonging, and self-esteem (Navarrete \& Jenkins, 2011). In this study, the reliability 
estimate was .85 .

Loneliness. The 20-item UCLA loneliness scale was used to assess subjective feelings of loneliness on a scale from 1 (I often feel this way) to 4 (I never feel this way; Russell, 1996). An example item is "I have nobody to talk to." Values were summed with high scores indicating high levels of loneliness. Alpha levels ranged from .89 to .94 (Russell, 1996). Although limited information is available on the psychometric properties of the scale with a Multiracial sample, it is one of the most commonly used loneliness scales, and has good test-retest reliability (Cramer \& Barry, 1999). With a diverse sample, including 38.4\% African-Americans and 28.3\% Latino Americans, the scale predicted depressive symptoms (VanderWeele, Hawkley, Thisted, \& Cacioppo, 2011). The reliability estimate was .96 in this investigation.

Perceived racial discrimination. A 20-item Perceived Ethnic Discrimination Questionnaire - Community Version measured experiences of discrimination (Brondolo et al., 2005). The scale has four subscales: Exclusion/Rejection (e.g., "Have others been nice to your face but said bad things behind your back?"), Stigmatization/Devaluation (e.g., Have others not trusted you?"), Work/School Discrimination (e.g., Have you been treated unfairly by teachers?) and Treatment/Aggression (e.g., "Have others threatened to hurt you?). Participants responded on a 5-point Likert scale ranging from 1 (never happened) to 5 (happens very often). All questions began with "Because of your racial background(s)..." Values are averaged, with high scores indicating significant discrimination. When used with Multiracial individuals, high interscale correlations were found, providing support for the use of a total score with a reliability estimate of .92 (Jackson, Yoo, Guevarra, \& Harrington, 2012). The reliability estimate for the current sample was .95 .

Others' surprise and disbelief regarding racial heritage. The 5-item Others' Surprise 
and Disbelief Scale assessed surprise and disbelief regarding the Multiracial person's heritage (Salahuddin \& O'Brien, 2011). An example item is “When I disclosed my racial background, someone acted surprised." There were two response scales for each item: frequency $(0=$ never happened to me; $5=$ happened to me more than 10 times $)$, and distress $(0=$ not at all distressed, $5=$ extremely distressed). Scores on the items were averaged into one mean score, with high scores representing higher rates of surprise and disbelief. An alpha of .83 was reported for a Multiracial sample (Salahuddin \& O'Brien, 2011). The reliability estimate in this study was 86.

Challenges with racial identity. The 5-item Challenges with Racial Identity subscale of the Multiracial Challenges and Resiliencies scale was used to assess lack of a sense of identity or belongingness with any racial group (Salahuddin \& O’Brien, 2011). A sample item is “Because I am Multiracial, I do not have a strong sense of who I am." Items were measured on a Likert scale ranging from 0 (strongly disagree) to 5 (strongly agree). A score was calculated by averaging items, with high scores indicating challenges with racial identity. The alpha coefficient for this scale for a Multiracial sample was .68 (Salahuddin \& O’Brien, 2011), and this scale was related positively to depression and frequency and stress associated with racist encounters, and negatively to social connectedness (Salahuddin \& O'Brien, 2011). The reliability estimate for the scale with the current sample was .72 .

\section{Results}

The sample was randomly split; 200 participants were used for the exploratory factor analysis and the remaining 297 were included in the confirmatory factor analysis. Prior to running the factor analyses, the factorability of the data set was deemed appropriate. The KaiserMeyer-Olkin Measure of Sampling Adequacy (KMO) score was .88 and the Bartlett's test of sphericity yielded a significant result, $\chi^{2}(120, N=200)=1686.64, p<.001$. 
A principal factor analysis with direct oblimin rotation was computed on all 30 items $(N$ $=200$ ). Eigen values and the percentage of variance accounted for by the first, second, third, fourth and fifth factors were $12.32,2.63,1.92,1.45$, and 1.03 , and $41.07 \%, 8.77 \%, 6.39 \%$, $4.83 \%$, and $3.44 \%$ respectively. Based on scree plots and the percentage of variance accounted for by factors, four principal factor analyses with direct oblimin rotations were computed, with two, three, four, and five factors extracted. Each factor solution was considered to identify the solution with the highest loading items with fewest cross-loadings, robust variance explained, conceptual clarity, and each factor containing at least 4 items (to increase the likelihood of factor reliability; Tabachnick \& Fidell, 2007). To further examine the factors obtained, a separate parallel analysis was conducted with 1,000 randomly permutated data sets (O'Connor, 2000). The analysis suggested the presence of three factors. Based upon the aforementioned criteria, along with the parallel analysis, the three-factor solution was selected.

To retain only the most robust items on the measure, only the four highest loading items on each factor were retained (Tabachnick \& Fidell, 2007). For the final 12 items, The KaiserMeyer-Olkin Measure of Sampling Adequacy (KMO) score was .88 and the Bartlett's test of sphericity yielded a significant result, $\chi^{2}(66, N=200)=2450.83, p<.001$, which indicated that the data were factorable. The scree plot indicated a 2, 3, or 4 factor solution with these items. In line with the parallel analysis, a final three-factor exploratory factor analysis was conducted with these 12 items. Each of these items loaded above .64 on a single factor, and did not load above .18 on more than one factor. Factor loadings can be found in Table 1. Items collectively accounted for $70.19 \%$ of the variance, with the first factor accounting for $44.14 \%$, the second, 15.69\%, and the third, 10.37\%. Eigen values for the first three factors where 5.30, 1.88, and 1.24 (with the eigen value for the fourth factor being .57). 
Before conducting confirmatory factor analyses, tests for skewness and kurtosis were conducted using Mplus to ensure that the data from the second randomly selected sample $(N=297)$ did not violate the assumption of multivariate normality. Significance rates for both skewness and kurtosis were below .05, indicating that the data deviated from the assumption of multivariate normality. Thus, multiple linear regression (MLR) estimation was used for all subsequent analyses as it allows for deviations from normality (Satorra \& Bentler, 1988). The MLR adjusted scores by a scaling factor of 1.15 .

To test the three-factor model, a confirmatory factor analysis was conducted using Mplus. Model fit was evaluated using the root-mean-square error of approximation (RMSEA), Comparative Fit Index (CFI) and Tucker-Lewis Index (TLI). Good model fit is indicated by RMSEA values less than .06 and acceptable fit as less than .08 . CFI/TLI values greater than or equal to .95 are good, whereas values greater than or equal to .90 are acceptable $(\mathrm{Hu} \&$ Bentler, 1999; Weston \& Gore, 2006). After running the CFA with the 12-item measure, composed of 3 subscales, the fit indices were adequate: $\chi^{2}(51, N=297)=78.47, \mathrm{p}<.01, \mathrm{RMSEA}=.04, \mathrm{CFI}=$ .97 , and TLI $=.97$. All items had factors loadings above .6 for each of their respective factors and were significant (see Table 1). Next, reliability estimates were calculated for each of the factors using the total sample $(N=497)$.

The first factor, behavioral invalidation, assessed experiences of invalidation due to behaviors that deviated from perceived racial norms in behaving (e.g., "I am excluded from a racial group that I feel connected to because I do not "behave" like a typical member of that racial group(s);" $\alpha=.81$ ). The second factor, phenotype invalidation, assessed experiences of invalidation prompted by phenotype $(\alpha=.85)$. In these cases, racial phenotype did not match a perceived racial prototype for appearance, provoking racial identity invalidation, e.g., "My 
physical features (e.g., skin color, hair texture, eye shape, eye color) lead people to assume that I am not the race(s) that I identify with." Finally, the last factor, identity incongruent discrimination, assessed discriminatory experiences that were based on a perceived identity that did not match self-identity (e.g., "Others apply racial stereotypes to me that do not apply to the racial group(s) that I identify with;" $\alpha=.82$ ). Correlations between frequency and distress components of the Racial Identity Invalidation scales were moderate (Behavior Invalidation $=.46 ;$ Phenotype invalidation $=.39 ;$ Identity Incongruent Discrimination $=.53$ ) and all were significant at the .001 level.

Concurrent Validity. Correlations among the factors and validity measures were calculated. The Bonferroni correction was applied: significance levels below .008 were considered significant (See Table 3). The three factors exhibited moderate to high correlations and all were related positively to discrimination, cultural homelessness, loneliness, and challenges with racial identity; all except phenotype invalidation positively related to depression. None of the subscales related to self-esteem.

Group Differences. Independent samples t-tests were computed to compare levels of racial invalidation across Black/White $(N=118)$ and Asian/White $(N=166)$ individuals. Levels of behavior invalidation were higher for Black/White $(M=3.32 ; S D=1.17)$ than for Asian/White $(M=2.38 ; S D=1.09)$ Multiracial individuals $(t(282)=3.07, p<.01)$. The subgroups did not differ in levels of phenotype invalidation $(t(282)=.60 p>.05)$ or identity incongruent discrimination $(t(282)=-.77 p>.05)$.

Independent samples t-tests were calculated to compare levels of invalidation between women $(N=372)$ and men $(N=119)$. There were not enough non-binary individuals represented in the data to include in the analyses. Levels of behavior invalidation were higher for women $(M$ 
$=2.99 ; S D=1.18)$ than for men $(M=2.57 ; S D=.97 ; t(489)=-3.46, p<.01)$. Levels of phenotype invalidation were higher for women $(M=3.68 ; S D=1.21)$ than for men $(M=3.41$; $S D=1.12 ; t(489)=-2.11, p<.05)$. There were no gender differences in identity incongruent discrimination $(t(489)=.13 p>.05)$.

Competing Model. Next, a competing bifactor model was tested $(N=297)$. A bifactor model would suggest that a general factor assessing invalidation accounts for variance, along with domain-specific factors accounting for additional variance (Reise, Moore, \& Haviland, 2010). The 12-item bifactor model exhibited good model fit: $\chi 2(42, N=297)=57.25, \mathrm{p}>.05$, RMSEA $=.04, \mathrm{CFI}=.99$, and TLI $=.94$. All factor loadings for the general factor and all but two domain-specific factor loadings were significant (see Table 2). To compare the bifactor and three-factor models, a Satorra-Bentler scaled chi square difference test was conducted (Satorra, 2000). This scaled test is used in lieu of the traditional chi square difference test when MLR estimation is employed. First, the difference test scaling correction was computed to be -1.46 . This value was used to compute the Satorra-Bentler chi square difference test, which revealed that the bifactor model provided superior fit to the three-factor model: $\chi^{2}$ diff $(9)=19.58, p<.05$. Additionally, the full Racial Identity invalidation total scale $(\alpha=.86)$ related to all of the validity measures in the hypothesized directions: depressive symptoms, self-esteem, racial homelessness, loneliness, discrimination, and challenges with racial identity.

Incremental Validity Tests. Because of the superiority of the bifactor model, the total invalidation scale was utilized for incremental validity testing $(N=497)$. Four hierarchical regressions were conducted to test the significance of racial invalidation in predicting each of the minority-stress related outcomes above the contributions of the Surprise and Disbelief subscale (i.e., depressive symptoms, self-esteem, racial homelessness, and loneliness). The Invalidation 
scale predicted variance in each of the four outcome measures beyond variance explained by the Surprise and Disbelief subscale (see Table 4), although the magnitude of difference was small with regard to depressive symptoms and self-esteem.

Mediation Model. According to the Minority Stress Theory, experiences of racial identity invalidation are internalized (operationalized here as challenges with racial identity, i.e., a lack of sense of identity and/or not belonging in a particular racial group), and subsequently affect depressive symptoms and self-esteem. Therefore, meditational models were tested (see Figures 1, 2, 3, and 4). To assess whether challenges with racial identity completely mediated relations between racial identity invalidation and depressive symptoms, nested models were compared. Model 1 included indirect links between invalidation and depression (see Figure 1; $\chi^{2}$ $=3.32, d f=1, p=.07, n s, C F I=.99, N F I=.98, R M R=.35, R M S E A=.07,90 \%$ CI $[.00, .16]$ ); was nested within Model 2 where direct links were included between invalidation and depression (see Figure 2); because this model is just identified, it can be assumed to have a chi square of 0 , perfect fit indexes, and a degree of freedom value of zero. The scaling correction factor was approximately one, indicating no issues with normality and subsequently no need to adjust the chi square difference test. A chi-square difference test comparison of the two models yielded a $\Delta \chi^{2}=3.32, \Delta d f=1, p>.05$, which indicated that the models did not significantly differ, and the addition of the direct links between invalidation and depressive symptoms did not explain additional variance, beyond that explained by challenges with racial identity. This finding suggested that challenges with racial identity fully mediated the relationship between racial identity invalidation and depressive symptoms.

To assess whether challenges with racial identity completely mediated relations between racial identity invalidation and self-esteem, nested models were compared. Model 1 included 
only indirect links between invalidation and self-esteem (see Figure $3 ; \chi^{2}=2.72, d f=1, p>.05$, $n s, C F I=.99, N F I=.99, R M R=.18, R M S E A=.06,90 \%$ CI $[.00, .15])$; was nested within Model 2 where direct links were included between invalidation and self-esteem (see Figure 4); and because this model was just identified, it was assumed to have a chi square of 0 , perfect fit indexes, and a degree of freedom value of zero. The difference test scaling correction was .96. A Satorra-Bentler chi-square difference test comparison of the models yielded a $\Delta \chi^{2}=2.72, \Delta d f=$ $1, p>.05$, which indicates that Model 1 and Model 2 did not differ, and the addition of the direct links between invalidation and self-esteem did not explain additional variance, beyond that explained by challenges with racial identity. This suggests that challenges with racial identity fully mediated relationships between racial identity invalidation and self-esteem.

Test-retest Reliability. Finally, to obtain additional reliability estimates and to compute test-retest reliability, 79 individuals who submitted their contact information to the researchers to enter the lottery to win a gift certificate were invited to complete the Racial Identity Invalidation measure for a second time (between two weeks to two months after their initial participation). Participants were offered an additional chance at winning a \$25 gift certificate; 39 individuals completed the original 30 -item measure a second time, resulting in a $49.4 \%$ response rate. The means, standard deviations, ranges, internal consistencies, test-retest reliabilities, and effect size estimates are reported in Table 5. The internal consistency estimates for all of the subscales ranged from .77 to .84 , and the two-month test-retest reliability estimates ranged from .74 to .89 . Cohen's D effect size, indicating the magnitude of the differences in scores one subscales across time, was small.

\section{Discussion}

The purpose of the current study was to create a psychometrically sound measure of 
experiences of racial identity invalidation for use with Multiracial individuals. The Racial Identity Invalidation instrument demonstrated adequate psychometric properties when used with Multiracial adults of diverse racial backgrounds. Exploratory factor analyses indicated a threefactor structure model, including Behavioral Invalidation, Phenotype Invalidation, and Identity Incongruent Discrimination, and this model was supported by a confirmatory factor analysis. A comparison of this model with an alternate bifactor model indicated that the bifactor model (consisting of one overall general factor and three specific subfactors) was superior to the threefactor model. Generally, participants reported moderate amounts of phenotype invalidation and low-moderate amounts of behavior invalidation and identity incongruent discrimination. Internal consistency estimates and test-retest reliability for the subscales of the instrument were moderate to high. Each of the invalidation factors had adequate test-retest reliability after a two week to two-month period. Furthermore, effect sizes indicating differences between mean values on each factor across this period were small.

The bifactor model for our scale advances conceptual understandings of racial identity invalidation and allows future researchers and therapists to use both total and subscale scores. The first factor, behavior invalidation, highlights experiences where the Multiracial person's non-racially stereotypical actions or behaviors led others to invalidate their racial identity. This factor was consistent with forms of invalidation arising in past research (Khanna, 2004; Khanna, 2010; Romo, 2011), which has found that because others inaccurately conflate behaviors with racial group membership, those not fulfilling certain behavioral stereotypes are subject to the racial identity invalidation. The second factor, phenotype invalidation, assessed invalidating experiences based on appearance, which occurs when a Multiracial person's phenotype leads others to assume that they are a different race than that which they personally identify. This 
factor is also consistent with previous invalidation research (e.g., Khanna, 2004; Rockquemore \& Brunsma, 2002; Townsend et al., 2009; Yoo et al., 2015). The last factor, identity incongruent discrimination, included experiences where Multiracial individuals were discriminated against for a race with which they did not identify. This type of discrimination has yet to be identified in existing research on Multiracial individuals.

Moreover, the validity of the measure was supported by correlations with theoretically related variables. In line with minority stress theory, all factors except phenotype invalidation were related to depressive symptoms (Coleman \& Carter, 2007), and all factors were associated with challenges to racial identity, racial homelessness, and loneliness (Franco et al., 2016; Khanna, 2010; Romo, 2011). All factors also related to racial discrimination, a more traditional form of minority stress, which suggested the relevance of invalidation to a minority stress model (Meyer, 2003). Although none of the subscales related to self-esteem, the full Invalidation scale related to self-esteem and all of the other outcomes in expected directions. Also, when the invalidation factors were entered into regressions after the contributions of the Surprise and Disbelief Scale were considered, the factors uniquely contributed to the prediction of depressive symptoms, self-esteem, racial homelessness, and loneliness, suggesting that the newly developed racial invalidation scale represents a distinct construct (although the contributions were quite small with regard to depressive symptoms and self-esteem).

Path analyses indicated that challenges with racial identity mediated relationships between invalidation and depressive symptoms and self-esteem. This finding is aligned with the minority stress theory that indicates that minority individuals may internalize an environment that is hostile toward their stigmatized identity, which subsequently affects their mental health and self-esteem. In line with the minority stress model, a more comprehensive conceptual model 
which outlines invalidation as an initial catalyst precipitating the link between compromised sense of racial identity and well-being is presented. Thus, challenges with racial identity is conceptually different from, but still significantly linked to, invalidation in that it represents the internalization - subjective negative feelings about identity and belongingness - brought on by an external discriminatory experience (e.g., racial identity invalidation).

Furthermore, in comparison to previous measures that may have assessed some aspects of invalidation (e.g., Salahuddin \& O’Brien, 2016; Yoo et al., 2016), the invalidation scale provides a more comprehensive assessment of this stressor. It addresses the two most common invalidation catalysts in the literature, appearance and behavior, and its subscales allow for investigations of the unique impact of each of these types of racial identity invalidation. Because behaviors may change over time, whereas appearance may be more stagnant, each of these may have divergent trajectories throughout the Multiracial individual's lifespan. Furthermore, because appearance is evaluated more immediately than behavior, each may have different implications. For example, phenotype invalidation may elucidate automatic stereotyping experienced by Multiracial individuals. In addition to substantiating previous literature, the Racial Identity Invalidation scale also expands the measurement of this construct by uncovering new ways that invalidation manifests - through identity incongruent discrimination. Though research has highlighted the negative impact of discrimination for Multiracial individuals (e.g., Jackson et al., 2012; Salahuddin \& O’Brien, 2011), it has not yet accounted for the identity incongruent experiences of prejudice that Multiracial people may experience. Previous research indicated that the race that Black/White Multiracial individuals are most likely to be perceived as is Hispanic (Feliciano, 2016), and thus, for Multiracial discrimination research to better reflect the lived realities of Multiracial individuals, not only their self-identified, but also their perceived 
race must be considered. This construct may also have legal implications for Multiracial individuals; the Civil Rights Act of 1964 protects people from employment discrimination based on race, but does not explicitly outline protections passed on perceived race (Civil Rights Act, 1964). For example, in 2010, Nathanial Burrage, a Black/White Multiracial man, had his employment discrimination case dismissed because his employers discriminated against him because they perceived him as Hispanic.

In line with our hypotheses, behavioral invalidation was higher for Black/White than for Asian/White Multiracial individuals. Considering that Black/White Multiracial people report experiencing more invalidation from Black people than White people (Franco \& Franco, 2015), it may be that African-American populations' strong cultural mistrust towards Whiteness may be fueling the invalidation of Black/White Multiracial people's racial identities—whenever their behaviors are aligned more with White or mainstream culture (Whaley, 2001). Eastern cultures, grounded in religious and philosophical roots, also have been found to have more tolerance for ambiguities and contradictions in self and in behaviors, termed dialectical self-views (SpencerRodgers et al., 2004), which has been found to be protective for Asian Multiracial individuals (Sanchez, Shih, \& Garcia, 2009). Surprisingly, no differences in phenotype invalidation or identity incongruent discrimination were found across racial groups, although differences in phenotype invalidation were expected based on previous literature (e.g., Ho et al., 2011). Interestingly and importantly, women reported higher levels of behavior and phenotype invalidation than men - a finding that is consistent with some prior research (e.g., Rockquemore \& Brunsma, 2002). It is possible that racial identity invalidation may be more salient to women, and especially Multiracial women, because of others' preoccupation with their racially ambiguous appearance (Davenport, 2016; Stors, 1999). Alternatively, Multiracial women may 
experience more invalidation because women, generally, are perceived as less threatening than men, and thus may be the recipients of racially invalidating comments more often than men. Moreover, the intersection of sexism and racism may play a role in women being the targets of racial identity invalidation at a higher rate and/or level of intensity than men. These hypotheses are speculative, and future research might clarify why Multiracial women may be more likely to experience invalidation.

Though both the frequency and distress scales for invalidating events were administered to participants, frequency responses were utilized for the development of the measure. This allows the current measure to align with previous research on invalidation, which has conceptualized the stressor as an experience that occurs through interaction with the outside world (Campbell \& Troyer, 2007; Rockquemore \& Brunsma, 2002). In contrast to distress, frequency of invalidation may not necessarily indicate compromised well-being, as factors such as cognitive framing of invalidating experiences, coping and racial identity salience may mitigate the relationships between frequency and distress of invalidation. Capturing the frequency of invalidating experiences may be useful for researchers trying to uncover mediating mechanisms that inhibit the negative internalization of invalidating experiences. Alternatively, to uncover the negative impact of invalidating experiences, the distress scale may be most promising.

The generalizability of the data is limited by characteristics of the sample: mostly female, young, educated, healthy, and wealthy. The well-adjusted nature of this sample might explain why some relationships between invalidation and mental health/well-being outcomes were small, and a clinical sample might evince stronger relationships. The majority of participants possessed some degree of White heritage. The strategic recruitment of participants from websites and listservs catering to Multiracial individuals, and from a diverse mid-Atlantic university, and 
participants willingness to engage in a study on Multiracial individuals, may suggest that the participants' racial identity was particularly salient and that individuals from the sample had access to a Multiracial community. Thus, the findings are not generalizable to all Multiracial people and factors that might emerge with a sample of Multiracial individuals that is older, of lower socioeconomic status or of poorer mental health might differ from those arising in this study.

Although the Racial Identity Invalidation scale was developed to capture racial identity invalidation experiences across Multiracial compositions, and its creation incorporated feedback from experts whose research examined experiences of individuals of various Multiracial compositions, the items may best capture invalidation among Black/White Multiracial individuals. This may have occurred because items were informed by a review of the extant literature on invalidation, which disproportionately focuses on invalidating experiences of Black/White Multiracial individuals (Charmaraman et al., 2014). Future research is needed to examine the invalidating experiences of Multiracial individuals of varied racial backgrounds. For Latinx and Asian Multiracial individuals, it is likely that knowledge of language and cultural practices may contribute to experiences of invalidation.

Another limitation to this study was that the measure did not allow for the direction of the invalidation to be identified as Multiracial individuals identify with and experience invalidation when they identify with Monoracial groups and also when they identify as Multiracial (Franco et al., 2016). This means that degree of invalidation reported may perhaps reflect a composite of invalidating experiences across various identities - though this may lead to some obfuscation of measurement, it also allows the measure to accommodate the complexities and variability inherent in a Multiracial identity. 


\section{Future Directions}

For the full effects of invalidation to be understood, future research should incorporate the direction of the invalidation, i.e. whether a more privileged or stigmatized identity is being imposed on the Multiracial individual. For example, if a Multiracial person is perceived as White, though they may experience racial group isolation, they also may receive social benefits from this misperception. However, they also may be vulnerable to uncensored discriminatory comments to the extent that their identity as a person of color is concealable. In being perceived as a racial minority, they may have a difficult time being accepted within mainstream White society and also may be the target of racial discrimination.

The racial identity measure also may be useful in elucidating the manifestation of racial identity invalidation across contexts. For example, future research might examine reports of invalidation across school, work, home, or public settings, and also might incorporate how factors such as racial/ethnic composition of context, presence of other Multiracial individuals, and salience of race in a given environment may influence experiences of racial identity invalidation. This type of research would advance knowledge about the role context in experiences of racial identity invalidation and subsequent outcomes (Edwards, 2008).

Also, future research might investigate protective factors that reduce the impact of racial identity invalidation on mental health outcomes. Considering that challenges with racial identity plays a mediating role in relationships between invalidation and negative mental health and wellbeing, interventions might focus on helping Multiracial individuals develop a secure and positive sense of their racial identity in order to help them build resilience against racial identity invalidation. Researchers could examine if similar factors that lessen the effects of discrimination against Multiracial individuals might protect against invalidation as well, such as 
having an integrated sense of identity or parental racial socialization (Franco et al., 2016; Jackson et al., 2012). Furthermore, it would be useful to replicate findings of prior invalidation studies that used measures with limited psychometric validity using the current measure.

It may be particularly important to examine invalidation among certain age groups. Adolescence is a time when individuals are forming an identity, and when issues of belongingness are particularly important (Erikson, 1968). Thus, racial identity invalidation may be particularly threatening during adolescence to the extent that it destabilizes identity and contributes to isolation. Furthermore, examining invalidation among older populations may be meaningful, as these individuals faced more pressure to conform to Monoracial categories (Rockquemore et al., 2009). Relatedly, it may be meaningful to investigate how racially invalidating experiences affect racial identity over time. A longitudinal daily diary study would allow for an exploration of how experiences of invalidation directly affect identity at multiple points in time.

To conclude, this study found support for a psychometrically valid measure of racial identity invalidation for use with Multiracial individuals. It is hoped that this instrument will be used in future research seeking to examine racial identity invalidating experiences and mitigate their effects, ultimately promoting healthy racial identity and mental health for all Multiracial individuals. 


\section{References}

Binning, K. R., Unzueta, M. M., Huo, Y. J., \& Molina, L. E. (2009). The interpretation of Multiracial status and its relation to social engagement and psychological well-being. Journal of Social Issues, 65, 35-49. doi:10.1111/j.1540-4560.2008.01586.x

Brackett, K. P., Marcus, A., McKenzie, N. J., Mullins, L. C., Tang, Z., \& Allen, A. M. (2006). The effects of Multiracial identification on students' perceptions of racism. The Social Science Journal, 43, 437-444. doi:10.1016/j.soscij.2006.04.016

Brittian, A. S., Umaña-Taylor, A. J. \& Derlan, C. L. (2013). An examination of Biracial college youths' family ethnic socialization, ethnic identity, and adjustment: Do self-identification labels and university context matter? Cultural Diversity and Ethnic Minority Psychology, 19, 177-189. doi: 10.1037/a0029438

Brondolo, E., Kelly, P. K., Coakley, V., Gordon, T., Thompson, S., Levy, E., . . Contrada, R. J. (2005). The Perceived Ethnic Discrimination Questionnaire: Development and preliminary validation of a community version. Journal of Applied Social Psychology, 35, 335-365. doi: 10.1111/j.1559-1816.2005.tb02124.x

Buckley, T. R., \& Carter, R. T. (2004). Biracial (Black/White) women: A qualitative study of racial attitudes and beliefs and implications for therapy. Women \& Therapy, 27, 45-64. doi:10.1300/J015v27n01_04

Campbell, M. E. \& Troyer, L. (2007). “The Implications of Racial Misclassification by Observers." American Sociological Review, 72, 50-65.

Civil Rights Act of 1964, Pub.L. 88-352, 78 Stat. 241 (1964).

Charmaraman, L., Woo, M., Quach, A., \& Erkut, S. (2014). How have researchers studied multiracial populations? A content and methodological review of 20 years 
of research. Cultural Diversity And Ethnic Minority Psychology, 20, 336-352. doi:10.1037/a0035437

Coleman, V. H., \& Carter, M. M. (2007). Biracial self-identification: Impact on trait anxiety, social anxiety, and depression. Journal of Theory and Research, 7, 103-114. doi: $10.1080 / 15283480701326018$

Cooley, C. H. (1902). Human nature and the social order. New York: Scribner's.

Cramer, K. M., \& Barry, J. E. (1999). Conceptualizations and measures of loneliness: A comparison of subscales. Personality and Individual Differences, 27, 491-502.

Charmaraman, L., Woo, M., Quach, A., \& Erkut, S. (2014). How have researchers studied multiracial populations? A content and methodological review of 20 years of research. Cultural Diversity and Ethnic Minority Psychology, 20, 336-352. doi:10.1037/a0035437

Davenport, L. D. (2016). The role of gender, clas, and religion in Biracial Americans' racial labeling decisions. American Sociological Review, 81, 57-84. doi:

$10.1177 / 0003122415623286$

Edwards, L., (2008). Working with Multiracial clients in therapy: bridging theory, research, and practice. Professional Psychology: Research and Practice, 39, 192-201.

Edwards, L., \& Pedrotti, J. T. (2008). A content and methodological review of articles concerning multiracial issues in six major counseling journals. Journal of Counseling Psychology, 55, 411-418. doi: 10.1037/0022-0167.55.3.411

English, T., \& Chen, S. (2007). Culture and self-concept stability: Consistency across and within contexts among Asian Americans and European Americans. Journal of Personality and Social Psychology, 93, 478-490. doi: 10.1037/0022-3514.93.3.478

Erikson, E. (1968). Identity: Youth and crisis. New York: Norton. 
Feliciano, C. (2015). Shades of race: How phenotype and observer characteristics shape racial classification. American Behavioral Scientist, 60, 390419. http://doi.org/10.1177/0002764215613401

Flesch, R. (1948). A new readability yardstick. Journal of Applied Psychology, 32, 221-233. doi: $10.1037 / \mathrm{h} 0057532$

Franco, M. G., \& Franco, S. A. (2015). Impact of identity invalidation for Black Multiracial people: The importance of race of perpetrator. Journal of Black Psychology, 42, 530-548. doi: $10.1177 / 0095798415604796$

Franco, M. G., Katz, R., \& O’Brien, K. M. (2016). Forbidden identities: A qualitative examination of racial identity invalidation for Black/White Biracial individuals. International Journal of Intercultural Relations, 50, 96-109. doi: 10.1016/j.ijintrel.2015.12.004

Giamo, L. S., Schmitt, M. T., \& Outten, H. R. (2012). Perceived discrimination, group identification and life satisfaction among Multiracial people: A test of the rejectionidentification model. Cultural Diversity and Ethnic Minority Psychology, 18, 319-328. doi:10.1037/a0029729

Gullickson, A., \& Morning, A. (2011). Choosing race: Multiracial ancestry and identification. Social Science Research, 40, 498-512. doi:10.1016/j.ssresearch.2010.12.010

Herman, M. (2004). Forced to chose: Some determinants of racial identification among Multiracial adolescents. Child Development, 75, 730-748. doi:0009-3920/2004/75030006

Herman, M. (2010). Do you see what I am? Observers' backgrounds affect their perceptions of Multiracial faces. Social Psychology Quarterly, 73, 58-78. doi:10.1177/01902725103614 
Hill, M. E. (2002). Race of the interviewer and perception of skin color: Evidence from the multi-city study or urban inequality. American Sociological Review, 67, 99.

Ho, A. K., Sidanius, J., Cuddy, A. J. C., \& Banaji, M. R. (2013). Status boundary enforcement and the categorization of Black-White biracials. Journal of Experimental Social Psychology, 49, 940-943.

Ho, A. K., Sidanius, J., Cuddy, A. J. C., \& Banaji, M. R. (2013). Status boundary enforcement and the categorization of Black-White biracials. Journal of Experimental Social Psychology, 49, 940-943. doi:10.1016/j.jesp.2013.04.010

Ho, K., Sidanius, D. T., Levin, M. R., \& Banaji, M. R. (2011). Evidence for hypodescent and racial hierarchy in the perception of Biracial individuals. Journal of Personality and Social Psychology, 100, 492-506. doi: 10.1037/a0021562

Hu, L., \& Bentler, P. M. (1999). Cutoff criteria for fit indexes in covariance structure analysis: Conventional criteria versus new alternatives. Structural Equation Modeling, 6, 1-55. doi:10.1080/10705519909540118

Jackson, K. F., Yoo, H. C., Guevarra, R., \& Harrington, B. A. (2012). Role of identity integration on the relationship between perceived racial discrimination and psychological adjustment of Multiracial people. Journal of Counseling Psychology, 59, 240-250. doi: $10.1037 / \mathrm{a} 0027639$

Khanna, N. (2004). The role of reflected appraisals in racial identity: The case of Multiracial Asians. Social Psychology Quarterly, 67, 115-131.

Khanna, N. (2010). "If you're half Black, you're just Black": Reflected appraisals and the persistence of the one-drop rule. The Sociological Quarterly, 51, 96-121. doi:10.1111/j.1533-8525.2009.01162.x 
Lee, J., \& Bean, F. D. (2004). America's changing color lines: Immigration, race/ethnicity, and Multiracial identification. Annual Review of Sociology, 30, 221-242. doi: 10.1146/annurev.soc.30.012703.110519

Lou, E., Lalonde, R.N., \& Wilson, C. (2011). Examining a multidimensional framework of racial identity across different Biracial groups. Asian American Journal of Psychology, 2, 7990. doi: $10.1037 / \mathrm{a} 0023658$

Meyer, I. H. (2003). Prejudice, social stress and mental health in lesbian, gay, and bisexual populations: conceptual issues and research evidence. Psychological Bulletin, 129, 674697. doi: 10.1037/0033-2909.129.5.674

Miville, M. L., Constantine, M. G., Baysden, M. F., \& So-Lloyd, G. (2005). Chameleon changes: An exploration of racial identity themes of Multiracial people. Journal of Counseling Psychology, 52, 507-516. doi: 10.1037/0022-0167.52.4.507

O'Connor, B. P. (2000). SPSS and SAS programs for determining the number of components using parallel analysis and Velicer's MAP test. Behavior Research Methods, Instruments, \& Computers, 32, 396-402. http://dx.doi.org/10.3758/BF03200807

Navarrete, V., \& Jenkins, S. R., (2011). Cultural homelessness, multiminority status, ethnic identity development and self-esteem. International Journal of Intercultural Relations, 35, 791-804. doi:10.1016/j.ijintrel.2011.04.006

Nishimura, N. (2004). Counseling Biracial women: An intersection of multiculturalism and feminism. Women \& Therapy, 27, 133-145. doi: 10.1300/J015v27n01_09

Radloff, L. S. (1977). The CES-D Scale: A self-report depression scale for research in the general population. Journal of Applied Psychological Measures, 385-401. 
Reise, S. P., Moore, T. M., \& Haviland, M. G. (2010). Bifactor models and rotations: Exploring the extent to which multidimensional data yield univocal scale scores. Journal of Personality Assessment, 92, 544-559. doi: 10.1080/00223891.2010.496477.

Rockquemore, K. A., \& Brunsma, D. L. (2001). Beyond Black: Biracial identity in America. Thousand Oaks, CA: Sage.

Rockquemore, K. A., \& Brunsma, D. L. (2002). Socially embedded identities: Theories, typologies, and processes of racial identity among Black/White Biracials. The Sociological Quarterly, 43, 335-356. doi: 10.1111/j.1533-8525.2002.tb00052.x

Rockquemore, K. A., Brunsma, D. L., \& Delgado, D. J. (2009). Racing to theory or retheorizing race? Understanding the struggle to build a Multiracial identity theory. Journal of Social Issues. 65, 13-34. doi: 10.1111/j.1540-4560.2008.01585.x

Rockquemore, K. A., \& Laszloffy, T. A. (2003). Multiple realities: A relational narrative approach in therapy with Black-White mixed-race clients. Family Relations: An Interdisciplinary Journal of Applied Family Studies, 52, 119-128.doi: 10.1111/j.17413729.2003.00119.x

Romo, R. (2011). Between Black and Brown: Blaxican (Black-Mexican) Multiracial identity in California. Journal of Black Studies, 42, 402-426. doi:10.1177/0021934710376172

Root, M. P. P. (1992). Racially mixed people in America. Thousand Oaks, CA: Sage Publications.

Root, M. P. P. (1998). Experiences and processes affecting racial identity development: Preliminary results from the Biracial Sibling Project. Cultural Diversity and Mental Health, 4, $237-247$.

Rosenberg, M. (1979). Conceiving the self. New York: Basic Books. 
Roth, W. D. (2005). The end of the one-drop rule? Labeling of Multiracial children in Black intermarriages. Sociological Forum, 20, 35-67. doi: 10.1007/s11206-005-1897-0

Russell, D. W. (1996). UCLA loneliness scale (version 3): Reliability, validity, and factor structure. Journal of Personality Assessment, 1, 20-40.

Sanchez, D. T., Shih, M., \& Garcia, J. A. (2009). Juggling multiple racial identities: Malleable racial identification and well-being. Cultural Diversity \& Ethnic Minority Psychology, 15, 243-254. doi: 10.1037/a0014373

Salahuddin, N. M., \& O’Brien, K. M. (2011). Challenges and resilience in the lives of urban, Multiracial adults: An instrument development study. Journal of Counseling Psychology, 58, 494-507. doi: 10.1037/a0024633

Satorra, A. (2000). Scaled and adjusted restricted tests in multi-sample analysis of moment structures. In Heijmans, R.D.H., Pollock, D.S.G. \& Satorra, A. (eds.), Innovations in multivariate statistical analysis. A Festschrift for Heinz Neudecker (pp.233-247). London: Kluwer Academic Publishers

Satorra, A., \& Bentler, P. M. (1988). Scaling corrections for chi-square statistics in covariance structure analysis. Proceedings of the American Statistical Association, 308-313.

Sanchez, D. T. (2010). How do forced-choice dilemmas affect Multiracial people? The role of identity autonomy and public regard in depressive symptoms. Journal of Applied Social Psychology, 40, 1657-1677.

Sanchez, D. T., Shih, M., \& Garcia, J. A. (2009). Juggling multiple racial identities: Malleable racial identification and psychological well-being. Cultural Diversity and Ethnic Minority Psychology, 15, 243-254. doi: 10.1037/a0014373 
Sellers, R. M., \& Shelton, J. N. (2003). The role of racial identity in perceived racial discrimination. Journal of Personality and Social Psychology, 84, 1079-1092. doi: 10.1037/0022-3514.84.5.1079

Shih, M., \& Sanchez, D. T. (2005). Perspectives and research on the positive and negative implications of having multiple racial identities. Psychological Bulletin, 131, 569-591. doi:10.1037/0033-2909.131.4.569

Spencer-Rodgers, J., Peng, K., Wang, L., \& Hou, Y. (2004). Dialectical self and psychological well-being. Personality and Social Psychology Bulletin, 30, 1416-1432.

Storrs, D. (1999). 'Whiteness as stigma: Essentialist identity work by mixed-race women.' Symbolic Interaction 23, 187-212.

Suzuki-Crumly, J., \& Hyers, L. L. (2004). The relationship between ethnic identity, psychological well-being, and intergroup competence: An investigation of two biracial groups. Cultural Diversity \& Ethnic Minority Psychology, 10, 137-150.

Tabachnick, B. G., \& Fidell, L. S. (2007). Using multivariate statistics (5th ed.). Boston, MA: Allyn \& Bacon.

Tashiro, C. J. (2002). Considering the significance of ancestry through the prism of the mixedrace identity. Advances in Nursing Science, 25, 1-21.

Townsend, S. S. M., Markus, H. R., \& Bergsieker, H. B. (2009). My choice, your categories: The denial of Multiracial identities. Journal of Social Issues, 65, 185-204. doi:10.1111/j.15404560.2008.01594.x

U. S. Census Bureau. (2010). Overview of race and Hispanic origin: 2010. Retrieved December 8, 2012, from http://www.census.gov/prod/2001pubs/c2kbr01-1.pdf 
Vanderweele, T. J., Hawkley, L. C., Thisted, R. A., Cacioppo, J. T. (2011). A marginal structural analysis for loneliness: Implications for intervention trial and clinical practice. Journal of Consulting and Clinical Psychology, 79, 225-235. doi:10.1037/a0022610

Vivero, V. N., \& Jenkins, S. R. (1999). Existential hazards of the multicultural individual: Defining and understanding "cultural homelessness." Cultural Diversity \& Ethnic Minority Psychology, 5, 6-26.

Weston, R., \& Gore, P. A. (2006). A brief guide to structural equation modeling. Counseling Psychologist, 34, 719 -751. doi:10.1177/ 0011000006286345

Whaley, A. L. (2001). Cultural mistrust and mental health services for African Americans: A review and meta-analysis. The American Psychologist, 29(4), 513-531.

Yoo, H. C., Jackson, K. F., Guevarra, R. P., Jr., Miller, M. J., \& Harrington, B. (2015, October 12). Construction and initial validation of the Multiracial Experiences Measure (MEM). Journal of Counseling Psychology. Advance online publication. http://dx.doi.org/10.1037/cou0000117 
Table 1

Summary of Exploratory Factor Analysis for Racial Identity Invalidation Items

\begin{tabular}{|c|c|c|c|}
\hline & \multicolumn{3}{|c|}{ Factor Loadings } \\
\hline Item & $\begin{array}{c}\text { Behavior } \\
\text { Invalidation }\end{array}$ & $\begin{array}{l}\text { Phenotype } \\
\text { Invalidation }\end{array}$ & $\begin{array}{c}\text { Identity } \\
\text { Incongruent } \\
\text { Discrim }\end{array}$ \\
\hline
\end{tabular}

Because of the way I speak, others deny my racial group membership(s)

$\begin{array}{lll}.87 & -.02 & .08\end{array}$

I am excluded from a racial group that I feel connected to because I do not "behave" like a typical member of that racial group(s)

Others think that my interests are different than those of a typical 
People expect me to associate with members of a racial group that I do

.13

.18

$-.64$ not identity with

Note: Factor loadings over .60 appear in bold. 
Table 2

Principal Axis Factor Loadings and Confirmatory Factor Analysis Factor Loadings for Racial Identity Invalidation Scales

Bifactor Model

Item Content by Factor

PAF CFA General Group

Factor 1: Behavioral Invalidation

Because of the way I speak, others deny my racial group membership(s)

I am excluded from a racial group that I feel connected to because I do not "behave" like a typical member

of that racial group(s)

Others think that my interests are different than those of a typical member of my racial

When people hear my opinions, they make me feel like I do not belong in my racial group(s).

(1)

Cons

actor 2: Phenotype Invalidation

Others would not guess the race(s) that I identify with

People have reacted with surprise when I tell them the race(s) that I identify with

My physical features (e.g., skin color, hair texture, eye shape, eye color) lead people to assume that I am

not the race(s) that I perceive myself

People assume I am not a member of the racial group(s) that I identify with

$\begin{array}{llll}.87 & .72 & .53 & .49 \\ & & & \\ .85 & .72 & .49 & .60 \\ .80 & .69 & .54 & .41 \\ .70 & .66 & .55 & .36\end{array}$

Factor 3: Identity Incongruent Discrimination

Others call me racially-derogatory words that do not apply to the racial group(s) that I identify with

I am discriminated against based on a race that I do not identify with

Others apply racial stereotypes to me that do not apply to the racial group(s) that I identify with

People expect me to associate with members of a racial group that I do not identify with

$\begin{array}{llll}.89 & .74 & .29 & .70 \\ .84 & .79 & .37 & .70 \\ & & & \\ .82 & .71 & .46 & .55 \\ .77 & .79 & .38 & .69\end{array}$

$\begin{array}{llll}-.93 & .64 & .46 & .53 \\ -.87 & .70 & .53 & .54 \\ -.76 & .73 & .69 & .24 \\ -.64 & .75 & .65 & .33\end{array}$


Table 3

Correlations Among Scales, Reliabilities, Means, Standard Deviations, Actual Ranges, and Possible Ranges of Variables $(N=479)$

\begin{tabular}{|c|c|c|c|c|c|c|c|c|c|c|c|}
\hline Measures & 1 & 2 & 3 & 4 & 5 & 6 & 7 & 8 & 9 & 10 & 11 \\
\hline 1. Behavioral Invalidation & 1 & & & & & & & & & & \\
\hline 2. Phenotype Invalidation & $.35^{*}$ & 1 & & & & & & & & & \\
\hline 3. Identity Incongruent Discrimination & $.52 *$ & $.37 *$ & 1 & & & & & & & & \\
\hline 4. Depressive Symptoms & $.24 *$ & .08 & $.21 *$ & 1 & & & & & & & \\
\hline 5. Self-Esteem & -.11 & -.07 & -.06 & $-.64 *$ & 1 & & & & & & \\
\hline 6. Racial Homelessness & $.45^{*}$ & $.34 *$ & $.37 *$ & $.22 *$ & $-.17 *$ & 1 & & & & & \\
\hline 7. Loneliness & $.31 *$ & $.16^{*}$ & $.22 *$ & $.70^{*}$ & $-.59 *$ & $.33 *$ & 1 & & & & \\
\hline 8. Discrimination & $.41^{*}$ & $.12 *$ & $.50^{*}$ & $.30^{*}$ & -.06 & $.20^{*}$ & $.31 *$ & 1 & & & \\
\hline 9. Surprise and Disbelief & $.44 *$ & $.65 *$ & $.48^{*}$ & .08 & .03 & $.31 *$ & .10 & $.35^{*}$ & 1 & & \\
\hline 10. Challenges with Racial Identity & $.46^{*}$ & $.30^{*}$ & $.28 *$ & $.36^{*}$ & $-.38 *$ & $.65^{*}$ & $.44 *$ & $.19^{*}$ & $.24 *$ & 1 & \\
\hline 11. Full Invalidation Scale & $.80^{*}$ & $.75^{*}$ & $.79 *$ & $.23^{*}$ & $-.11 *$ & $.49^{*}$ & $.29 *$ & $.43^{*}$ & $.68^{*}$ & $.45^{*}$ & 1 \\
\hline Mean & 2.49 & 3.61 & 2.43 & 35.18 & 31.66 & 2.46 & 44.12 & 1.80 & 3.49 & 3.04 & 2.88 \\
\hline Standard Deviation & 1.11 & 1.20 & 1.07 & 10.82 & 6.14 & .56 & 14.82 & .68 & .99 & 1.14 & 1.15 \\
\hline Possible Range & $1-6$ & $1-6$ & $1-6$ & $20-80$ & $10-40$ & $1-4$ & $20-80$ & $1-5$ & $1-6$ & $1-6$ & $1-6$ \\
\hline Alpha & .85 & .85 & .82 & .92 & .91 & .85 & .96 & .95 & .86 & .72 & .86 \\
\hline
\end{tabular}

Note. $* \mathrm{p}<.008$ 
Table 4

Hierarchical Regressions for Tests of Incremental Validity of Invalidation Above Surprise and Disbelief

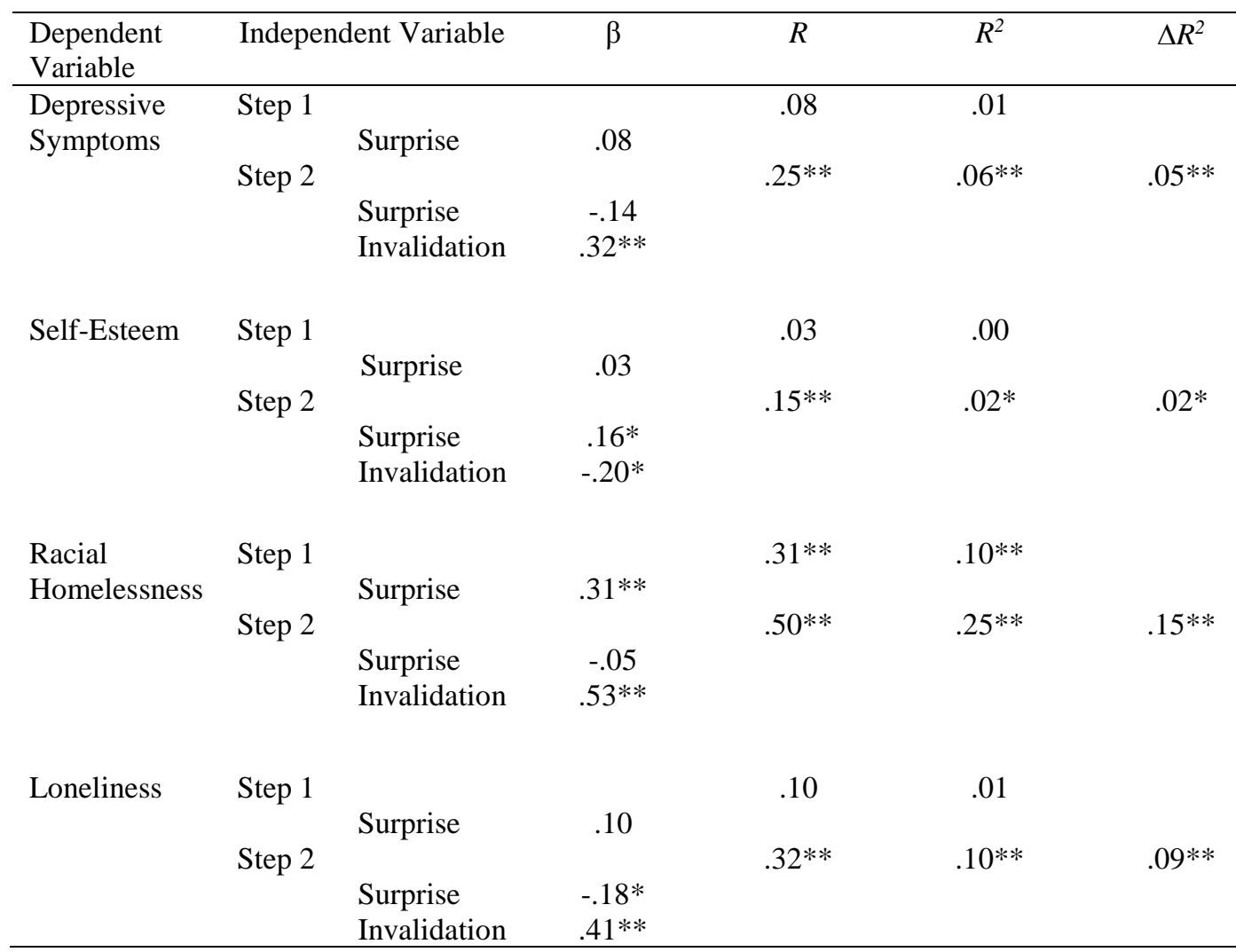

Note. "Surprise” indicates Surprise and Disbelief Scale and "Invalidation” indicates Racial Identity Invalidation Scale. $* p<.05$. ** $p<.01$. 
Table 5

Test-Retest Reliability Estimates for the Racial Identity Invalidation Subscales and Means, Standard Deviations, Actual Range, Possible Range, and Alpha Coefficients at Time $2(N=38)$

\begin{tabular}{lcccc}
\hline & $\begin{array}{l}\text { Behavioral } \\
\text { Invalidation }\end{array}$ & $\begin{array}{l}\text { Phenotype } \\
\text { Invalidation }\end{array}$ & $\begin{array}{l}\text { Identity } \\
\text { Incongruent } \\
\text { Discrimination }\end{array}$ & Total Scale \\
\hline Test Re-test Reliability & $.84^{*}$ & $.77^{*}$ & .79 & $.84^{*}$ \\
Time 2 Mean & 2.67 & 3.88 & 2.31 & 2.96 \\
Time 2 SD & 1.04 & 1.15 & .87 & .85 \\
Time 2 Possible Range & $1-6$ & $1-6$ & $1-6$ & $1-6$ \\
Time 2 Alpha & .88 & .75 & .89 & .74 \\
& & & & .08 \\
\hline
\end{tabular}

Note: ${ }^{*} p<.01$ 


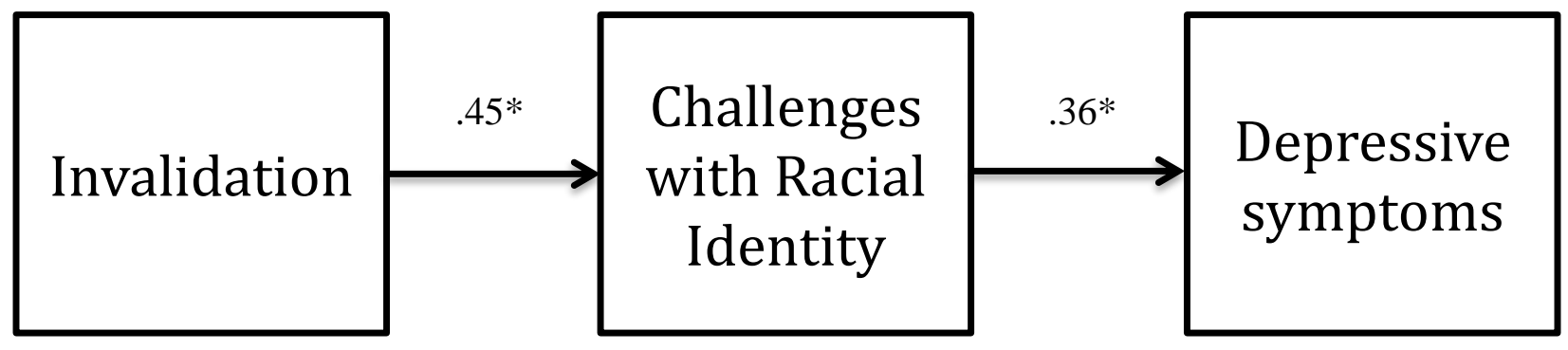

Figure 1. Indirect invalidation model predicting depressive symptoms with standardized solutions; $* p<.05$ 


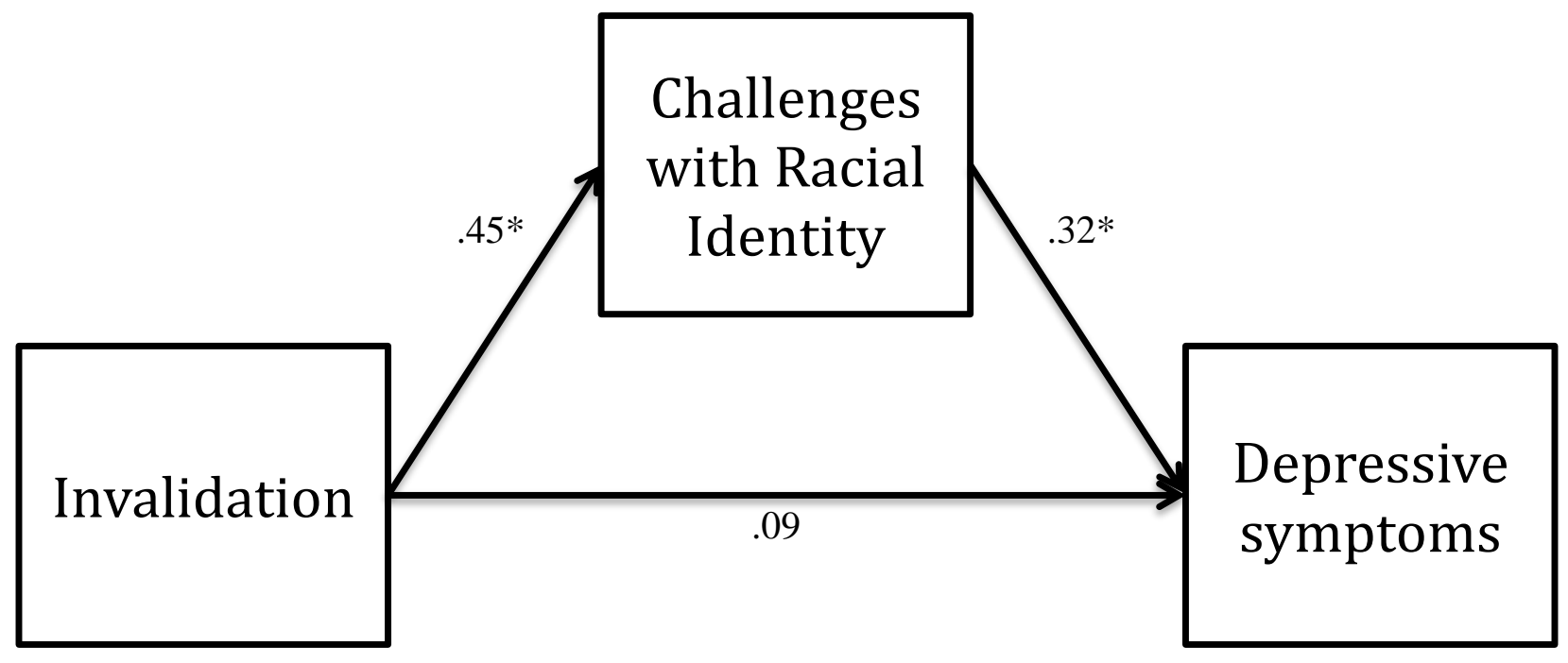

Figure 2. Direct invalidation model predicting depressive symptoms with standardized solutions; $* p<.05$ 


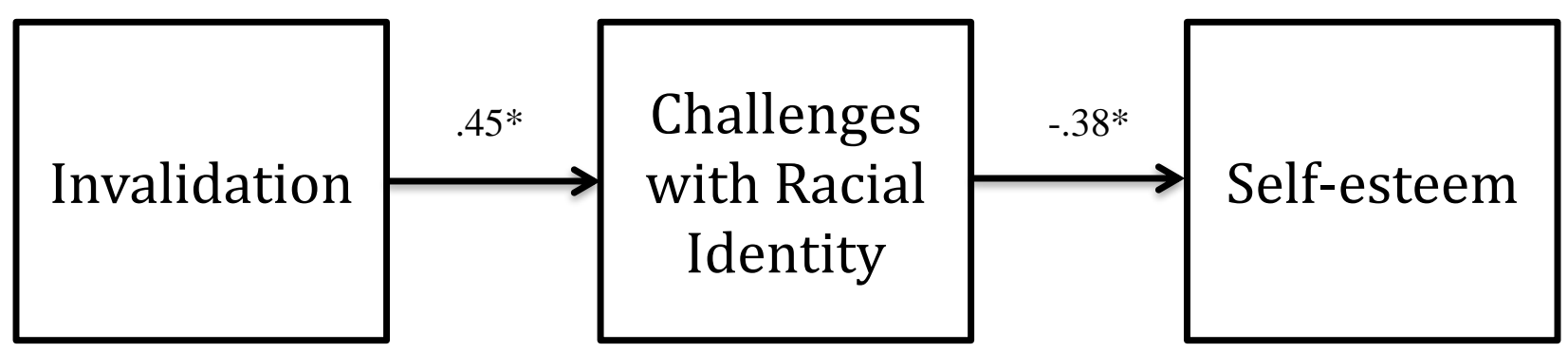

Figure 3. Indirect invalidation model predicting self-esteem with standardized solutions; ${ }^{*} p<.05$ 


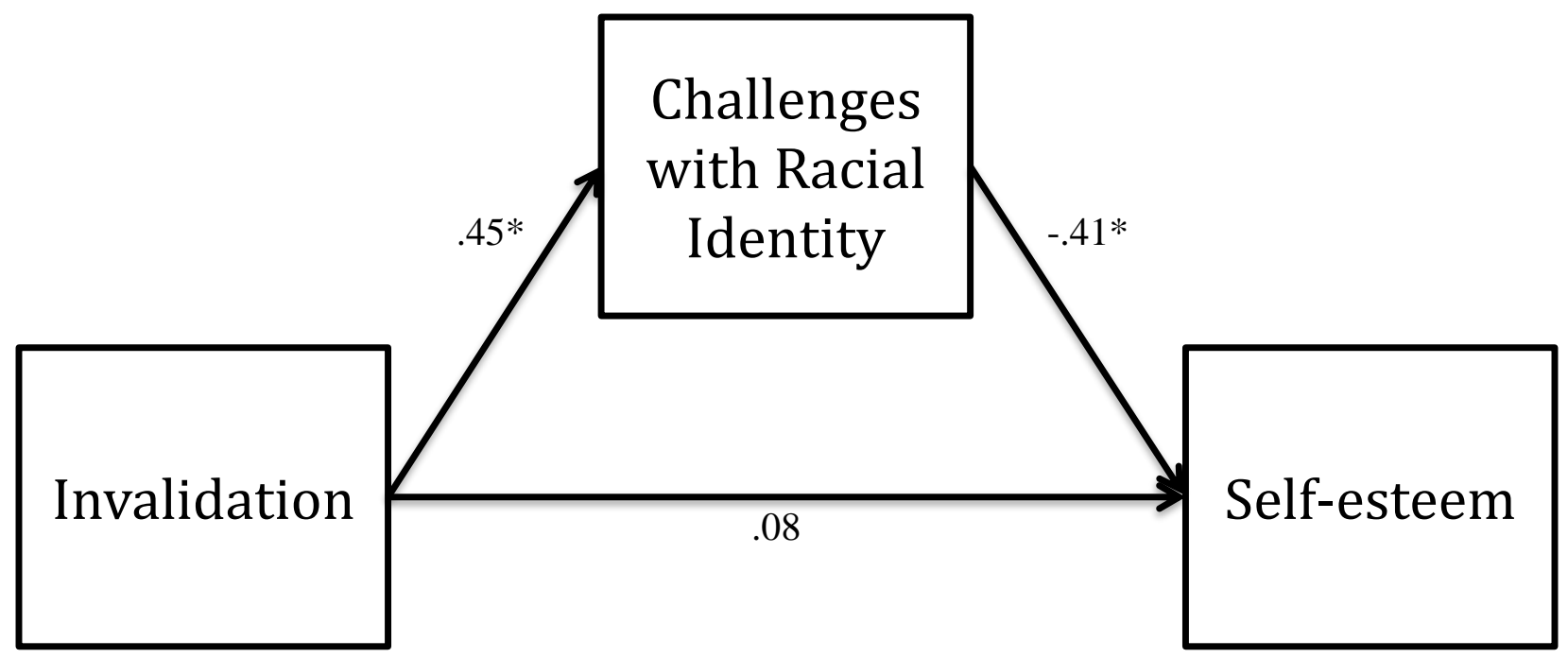

Figure 4. Direct invalidation model predicting self-esteem with standardized solutions; ${ }^{*} p<.01$ 